\title{
Prof. Dr. Mükerrem Usman Anabolu (10 Mayıs 1924 - 12 Mart 2021)
}

1983 yılında Ege Üniversitesi, Klasik Arkeoloji Anabilim dalında 2. sınıf öğrencisi iken 'Geometrik ve Arkaik Çağ Mimarlığı' dersinde tanıştım Mükerrem Usman Anabolu Hocamız ile. Bölümün diğer öğretim üyelerinden hatta belki tüm öğretim üyelerinden farklı idi, çünkü köpeği -ki hiçbir zaman köpek denmesini istemez hatta çok sinirlenirdi- Lucky ile gelirdi derslerimize. Lucky genellikle ders boyunca kürsünün yanında otururdu. Hatırladığım kadarıyla derslere Lucky ile girdiği için rektörlük ile sorun yaşamış ve gazetede 'Profesör Köpeği ile derse giriyor' başlıklı bir yazı çıkmıştı. O yıllarda evcil hayvan sahiplenme günümüzdeki gibi yaygın değildi. Mükerrem Hanım gazete haberinde çocuklarımdan farksız dediği Lucky’nin 9 yıllık alışkanlığı nedeniyle sınıfta kimseyi rahatsız etmediğini söylüyordu.

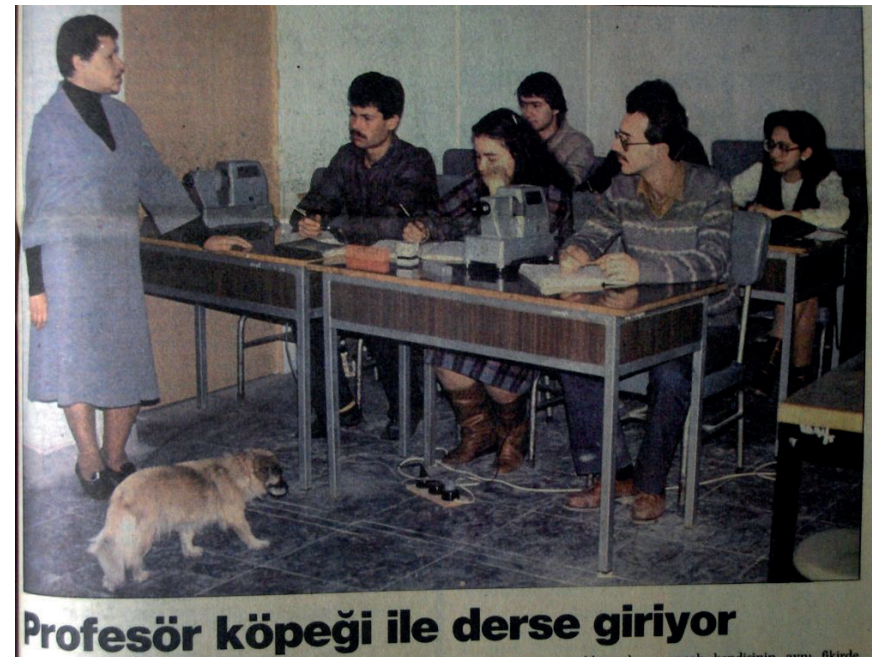

Prof. Dr. Mükerrem Usman Anabolu, İstanbul Teknik Üniversitesi’nde çalışırken 1974 yılında kendisine yapılan teklifle -doğduğu, büyüdüğü, okuduğu, çalıştı̆̆ı- İstanbul'dan eşyalarını gemiye yükleyip İzmir'e doğru yola çıkmıştı. Bu kararını kısa sürede verdiğini anlatmıştı. Anabolu İzmir'e geldiği yıllarda o zamanki adıyla Ege Üniversitesi Mühendislik Bilimleri Fakültesi'ne bağlı olan Mühendislik Mimarlık Akademisi, Mimarlık Bölümü’ne atanmıştı. Akademi daha sonra Güzel Sanatlar Fakültesine dönüştürülmüş ve M.U. Anabolu 
Güzel Sanatlar Fakültesi kadrosuna geçmişti. 1976 yılında Ege Üniversitesi'nde Sosyal Bilimler Fakültesi ve fakülte bünyesinde de Prof. Dr. M.U. Anabolu başkanlığında TarihCoğrafya ve Arkeoloji Bölümü kurulmuştu. Aynı yıl -1962 yılında kurulmuş olan- Arkeoloji Enstitüsü bu fakülteye bağlanmış ve başkanlığına da Prof. Dr. M.U. Anabolu getirilmişti. Arkeoloji Bölümü daha sonra 1979 yılında bağımsız bir bölüm olmuştur. Anabolu, 1991 yılında emekli oluncaya kadar bölümde çalışmıştır.

M.U. Anabolu İzmir'e gelmeden önce 1947-1973 yıllarında İstanbul Teknik Üniversitesi’nde Mimarlık Tarihi ve Restorasyon Kürsüsü’nde 26.5 yıl çalışmıştı 1955 yılında 'Antik Devir Küçük Asya Evleri' teziyle doçent, 1970 yılında 'Küçük Asya'da Bulunan Roma İmparatorluk Çağı Tapınakları' teziyle profesör olmuştur. Sohbetlerimizde Teknik Üniversite'de bulunduğu sürede en çok, asistanlığını yaptığ İtalyan Prof. Dr. Paolo Verzone ile anılarından bahsederdi. Anabolu, Verzone'nin 1957 yılında başlattığı Hierapolis kazılarında çalışmıştır. O'nun referansı ile İtalya ve Sicilya’ya defalarca gittiğini ve her kapının kendisine açıldığını anlatırdı.

Mükerrem hocamız hakkında bu yazıyı yazarken, P. Verzone'yi merak edip hakkında yazılanları okurken öğrencisi Afife Batur'un Verzone’yi anlattığı bir yazıya denk geldim. Şöyle diyordu Batur: 'Verzone bize mimarlı tarihini çok canlı bir anlatımla ve adeta yaşayan, hala devam etmekte olan bir olay olarak anlatırdl. Ben ondan ilk kez yapıların da fiziki çevrenin de kendisine özgü bir yaşamı olduğu duygusunu edindim'. Ben de aynı şeyleri Mükerrem Hanım için söyleyebilirim. Örneğin Didyma Apollon Tapınağı'nın geçirdiği depremi tiyatral anlatımla, o kadar canlı anlatmıştı ki.

Ege Üniversitesi, Edebiyat Fakültesi, Arkeoloji ve Sanat Tarihi Bölümü, Klasik Arkeoloji anabilim dalında mimarlık dersleri 2. sınıftan itibaren üç yıl Prof. Dr. M.U. Anabolu tarafından verilirdi. Hocamız önce dersin notlarını yazdırır sonrasında 'şimdi size Slayt Şov yapacağım' derdi. Kimi zaman kendisinin de yer aldığı yurtdışında, özellikle İtalya ve Sicilya' daki antik yerleşimlerde ve gezdiği şehirlerin görülmeye değer yerlerinde çekilmiş slaytların bizde merak uyandırdığını ve bu yerlerin ulaşılmaz olmadıkları duygusunu verdiğini düşünüyorum.

Mükerrem Hanım seyahat zevkini ve yeni yerler görme isteğini her zaman sürdürdü. İskandinav ülkelerine, Mısır'a, Hindistan'a, Güney Afrika'ya gitti. Bu seyahatlerin 1995 ile 2003 yılları arasında gerçekleştiğini biliyorum çünkü o yıllar Trakya Üniversitesi FenEdebiyat Fakültesi Arkeoloji Bölümü'ne geldiği yıllard1. İstanbul'dan Edirne’ye sekiz ders yılı boyunca her hafta Nümismatik ve Mimarlık derslerini vermek üzere Nişantaşı Valikonağı Caddesi'ndeki evinden İstanbul Otogarı'na, oradan da otobüs ile Edirne'ye fedakarca yılmadan geldi ve aynı gün geri döndü. Kalmasını isterdik ama giderdi... Trakya Üniversitesi'nde ders verdiği yıllar boyunca Hocamız Ege Üniversitesi'nden iki öğrencisini -beni ve İsmail Fazlıŏlu'nu- her bakımdan destekledi. 2002 yılında Edirne’de Arkeoloji 
Bölümünde ve Rektörlük Sergi Salonu'nunda Hindistan ve Güney Afrika seyahatlerinde çektiği fotoğraflardan bir de sergi açmıştı.

M.U.A. üniversite öğrenciliğine 1941 yılında İstanbul Üniversitesi'nde Tarih bölümünde başlamış, sonrasında -o yıllarda Tarih Öncesi ve İlkçağ Tarihi hocası olan Arif Müfid Mansel'in sayesinde diyerek anlattığ1- arkeolojinin büyüsüne kapılıp Klasik Arkeoloji’ye geçiş yapmıştı. Sohbetlerimiz sırasında asistanlığını yaptığı -hocanın deyişiyle Türkiye'yi aydınlatanlardan- hocası A.M. Mansel'den dinlediği Trakya tümülüslerini belirleme çalışmalarından, Alpullu ve Vize gibi tümülüs kazılarından, dolayısıyla Trakya arkeolojisine olan yakınlığından da söz ederdi ...

Mükerrem Hanım Ege Üniversitesi arkeoloji öğrencilerine de 3. sınıfta nümismatik dersi verirdi. Kendisi Türkiye'de ilk nümismatik derslerini veren Alman Prof. Clemens Emin Bosch'un danışmanlığında 'Mimarlık Tasvirleri Bulunan Anadolu Sikkeleri' adlı doktora tezi yapmıştır. Nümismatik dersinde her ders sayfalar dolusu yazdığım notlarıma yıllar sonra Trakya Üniversitesi'nde Nümizmatik dersi vermem istendiğinde bakacağımı bilemezdim. Hocanın kendi el yazısı ile hazırladığı 116 sayfalık bu nümizmatik ders notlarını -Trakya Üniversitesi'nden ayrılırken- bana vereceğini ise hiç aklıma getiremezdim. Trakya Üniversitesi’nde çalıştığı yıllarda ve ayrılırken kitaplarının bir kısmını Arkeoloji Bölüm Kütüphanesi’ne bırakması da bölüme verdiği önemli desteklerinden bir tanesi olmuştur.

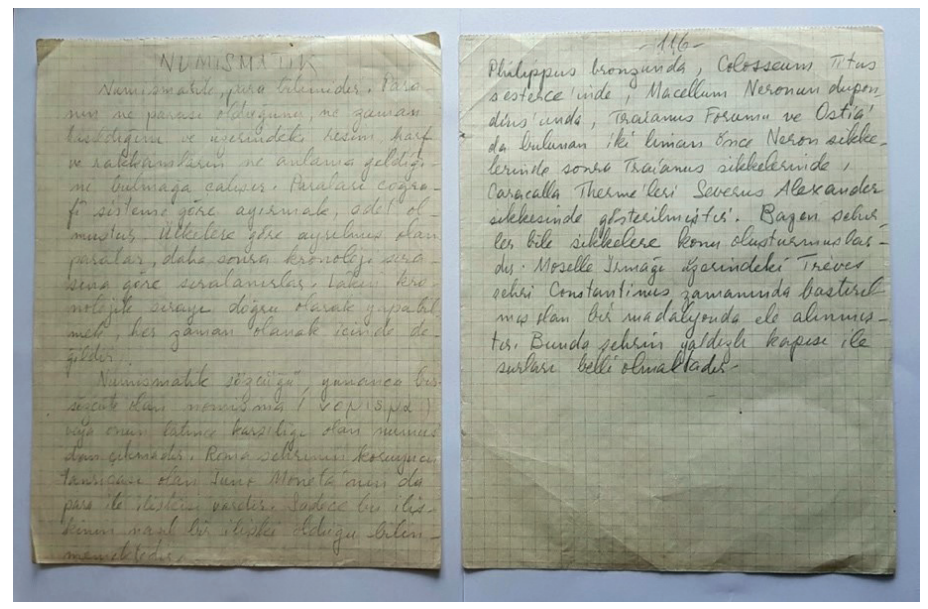

Hocamız İstanbul Üniversitesinde kendi öğrenciliğinde hocaları ile yaptıkları unutamadığı arkeoloji gezilerini, yıllar sonra Ege Üniversitesi’ndeki öğrencileri ile gerçekleştirerek bizim de unutamayacağız anılara dönüştürdü. Bir fark vardı onlar tüm sınıflar toplam sekiz kişi idiler, biz ise -1981 yılında YÖK'ün kuruluşu sonrası artırılan kontenjanlar ile- sadece bizim sınıfta 60 kişi idik. Bu gezi organizasyonlarının ne kadar zor olduğunu kendi öğrencilerim olduğunda anladım. Batı Anadolu'nun birçok kentini ve kutsal alanını hocamızla 
üniversitenin otobüsleri ile gezerdik. Daha sonra üçü (Yaşar Ersoy, Taciser Tüfekçi ve Zafer Derin) akademisyen olacak Ege Üniversitesi'nin dört kişi olan ilk arkeoloji öğrencilerini ise kendi arabasıyla gezdirdiğini anlatırdı.

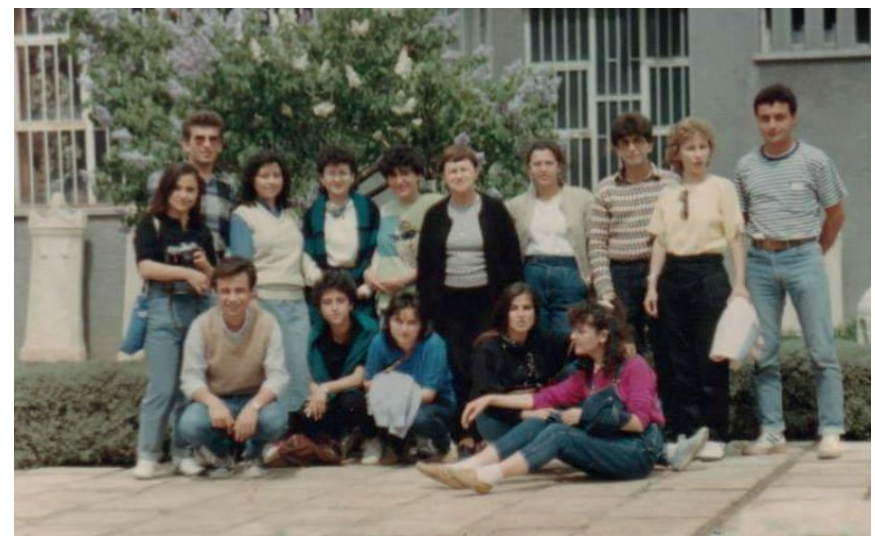

Ege Üniversitesi arkeoloji öğrencileri ile Afyon Arkeoloji Müzesi’nde, 19 Nisan 1986.

Akın Ersoy, Gülriz Kozbe, Binnur Gürler, Hande Kökten, Gürol Barın, Cumhur Tanrıver, Feriştah Soykal Alanyalı, İsmail Fazlığlu, Reyhan Körpe, Haluk Sağlamtimur, Eşref Abay, Gürcan Polat, Gül Gültekin Demir, Kaan İrem, Suat Ateşlier, Duygu Akar Tanrıver, Aynur Civelek -adlarını hatırlayabildiğim- Ege Üniversitesi’nde hocamızın öğrencisi olmuş diğer akademisyenlerdir.

M.U. Anabolu'nun her konudaki azimliliği yaşamı boyunca sürmüştü. Yabancı dilde eğitim yapan okullarda okumamasına rağmen yabancı dilleri öğrendiğini, Tünel'deki High School'a girebilmek için inatla çaba harcadığını anlatır ve yabancı dil bilmemeyi veya öğrenmemiş olmayı asla kabul etmezdi. Hatta bir kelimeyi yanlış telaffuz edenlere kızgınlığını hiç saklamazdı.

Doktorasını neredeyse tamamladığı bir zamanda Kanlıca'daki yalılarında boğaza bakan odasında yaşadığı olay ise başa çıkılması kolay bir durum olmasa gerek. Birden ortalığı kasıp kavuran bir firtınada camların kırılıp odadaki her şeyin birbirine girdiğini, masanın üzerinde duran tezinin bir kısmının uçtuğunu, bir kısmının kullanılmayacak duruma geldiğini ve sonrasında tezini yeniden yazdığını dinlemiştim kendisinden. Bunun benzeri başından geçen başka bir olayda ise -1946 yılından itibaren A.M. Mansel başkanlığında yapılan ve 9 sezon çalıştığı- Side kazısında bir gece çıkan fırtına sırasında, çadırın üstlerine çökmesini ve fotoğraf makineleri dahil her şeylerinin suda kalarak zarar görmesini anlatmıştı.

Prof. Dr. M.U. Anabolu Trakya Üniversitesi’nde ders verdiği yıllarda da çalışmalarına devam etti. 1999 yılında yayınladığı Yunan ve Roma Mimarlı̆̆, 2001 yılında yayınladığı 
İstanbul ve Anadolu'daki Roma İmparatorluk Dönemi Mimarlık Yapttları adlı kitaplarını özellikle mimarlık dersi öğrencileri için önemsemişti. 2003 yılında Türk Eskiçağ Bilimleri Enstitüsü Yayınlarından çıkan Antik Çağda Et ve Balık Pazarları ise son kitabıdır.

2000'li yılların başında Nişantaşı'nda yağlıboya resim kursuna devam etti. Kursa gittiği bir gün atölyede merdivenden düşmüş, belinde kırı olduğu çok sonra anlaşılmış ve ameliyat olmuştu. Çok zorlanmasına rağmen vakur duruşunu hep korudu.

Mükerrem Usman Anabolu Hocamız, İstanbul Üniversitesi’nde Clemens Emin Bosch (1889-1955), Helmuth Theodor Bossert (1889-1961), Arif Müfid Mansel (1905-1975), Kurt Bittel'ten (1907-1991) aldığı bilgi birikimini bizlere nasıl aktardıysa, şimdi de biz Hocamız ve Ege Üniversitesi Arkeoloji Bölümü’nün -Hocamızla aynı dönemde çalışmış olan- kaybettiğimiz çok değerli hocalarımız Erol Atalay (1935-1988), Güven Bakır (19392018), Tomris Bakır (1941-2020), Altan Çilingiroğlu (1944-2021) ile Hasan Malay (1948- ), Nuran Şahin (1948-), Ömer Özyiğit (1949-), Ersin Doğer (1951-) ve Önder Kazak'ın bizlere kattıklarını anlatıyor, bilgilerini paylaşıyoruz...

Hocamızı saygı ile hep hatırlayacağız.

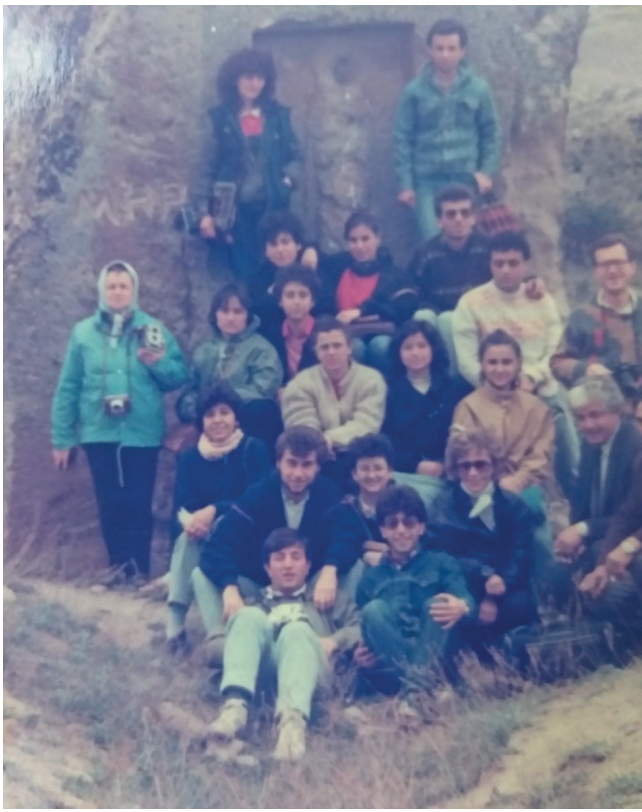

Ege Üniversitesi arkeoloji öğrencileri ile Küçük Kapıkaya’da, 20 Mart 1986. 


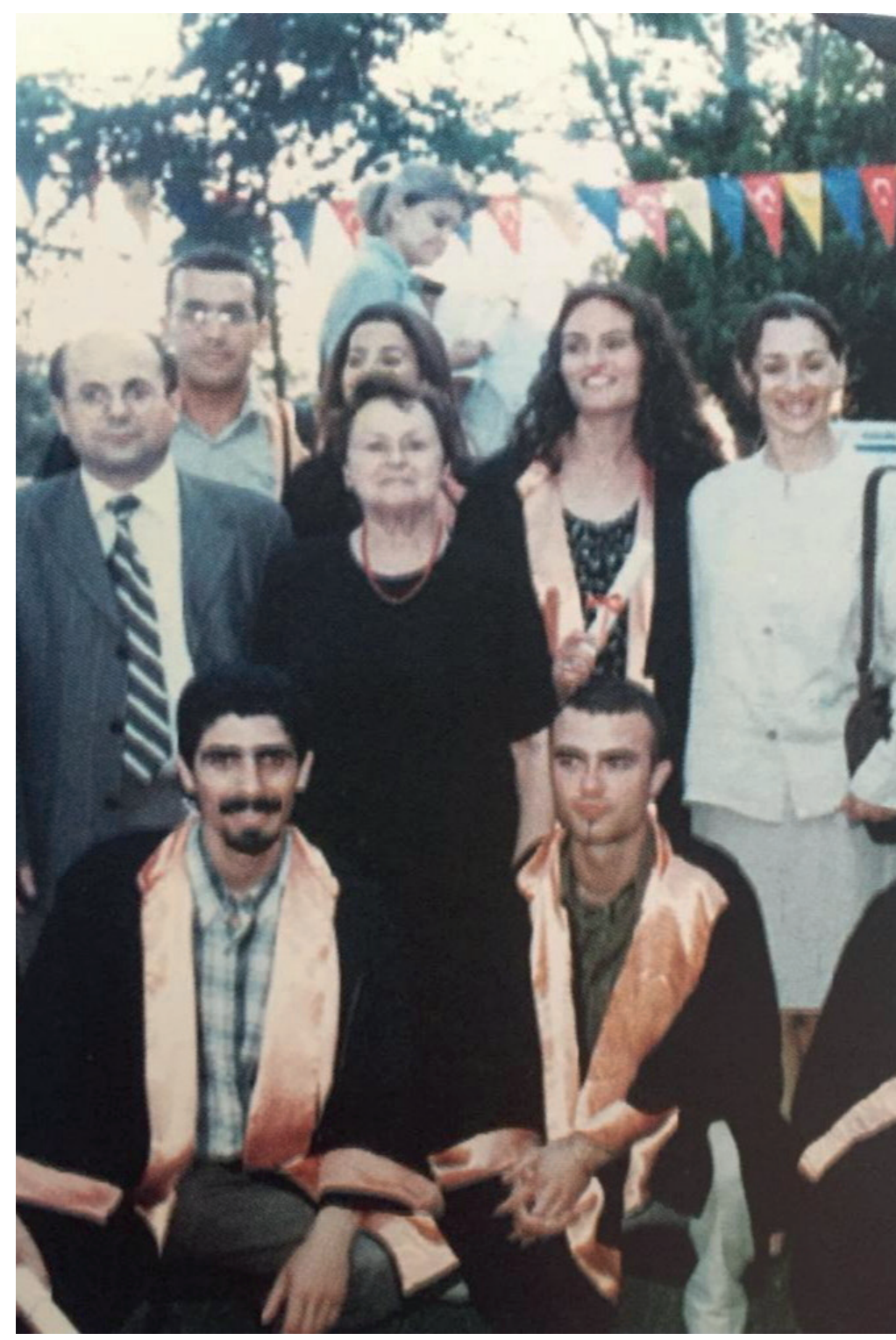

Trakya Üniversitesi'nden 2000'li yılların başından bir mezuniyet töreninde Ege Üniversitesi'nden öğrencileri olan o dönem Trakya Üniversitesinde Arkeoloji Bölümünde öğretim üyeliği yapan Dr. İsmail Fazlıŏlu (merhum) ve Dr. Iş̧k Şahin ile birlikte.

Dr. Işıı Şahin

TÜ Edebiyat Fakültesi, Arkeoloji Bölümü, Edirne 